\title{
INVESTIGATION OF FATAL CRASH TRENDS IN THE ARAB WORLD COMPARED WITH EU
}

\author{
HASHIM M.N. AL-MADANI \\ Department of Civil Engineering, University of Bahrain, Bahrain.
}

\begin{abstract}
Over three decades, vehicular and fatality related data are analysed and modelled for the Arab world and compared with $27 \mathrm{EU}$ countries. The data comparison and modelling include vehicle development, death frequencies and death rates per inhabitants and vehicles. The modelling is based on least-squares regression fit considering around two-third of a million gathered data points for 45 considered countries. The gathered Arab countries' data, as a whole, are thought to be presented for the first time; since no such data are yet observed in the literature. It is expected that an extra 117 million vehicles will be pumped into the global road network in a decade time from the earlier two regions. This sums to around 15\% of the current global vehicle population. While such an increase looks very encouraging for the vehicles' manufacturers, its environmental consequences and power consumption needs are surely not. While crash deaths in EU countries dropped from 74,876 during 1980 to 30,170 during 2011, that in the Arab countries increased from 22,145 victims to 37,736. The death record in the Arab countries is expected to further escalate to 54 thousand by the year 2022 based on mathematical models developed here. This represents around $45 \%$ increase since 2011 . That for 27 EU countries is expected to be within 10 and 20 thousand deaths, which is less than half of the 2011 record. The crash death rates in the EU countries decreased continuously during the past three decades and will continue doing so during the coming decade. That in the Arab world will also continue dropping gently during the coming decade. Currently, the overall rates for the EU countries is half that of the average Arab countries. The gap between the two will increase with the time if no proper counter action is considered. The rates in the Arab countries is quite misleading because of the clear difference in the vehicle ownership rate and average vehicle-miles travelled between Arab and EU countries. While the deaths rates per population in the $15 \mathrm{EU}$ countries are heading towards zero in a decade time; the rate in the Arab countries are expected to increase by $16 \%$. Many factors contribute to such high rates of traffic deaths in the Arab countries, as lack of measurable long-term safety plans, inconsistent handling of traffic safety strategies, poor research involvement and limited post-accident rehabilitation centres.

Keywords: Arab countries, crash death, death per vehicle, EU, fatality per population, roadway fatalities, traffic safety.
\end{abstract}

\section{INTRODUCTION}

Traffic crash data and database are well established in the developed countries. They are widely available and easily accessible for the researchers. This is not the case in most of the Arab and Asian countries. In fact, there is no single data base or reference covering the vehicular and traffic safety records for the past three decades. The case becomes more difficult to investigate when accidents involving vulnerable road users, as pedestrians, children, cyclists and motorcyclists to be considered as such data are not available except for few countries as Bahrain, Qatar, UAE, Jordan and Tunisia. Therefore, it was not possible to be considered in the comparison process. Nevertheless, this study tries to put together such data and compare their trends with European Union (EU) countries.

Arab world consists of 22 countries; 7 Arabian Peninsula ones, namely Saudi Arabia, Kuwait, Qatar, United Arab Emirates (UAE), Oman, Bahrain and Yemen; 5 Western Arabian ones, namely Mauretania, Morocco, Algeria, Tunisia and Libya; 4 Sham countries, namely Jordan, Syria, Lebanon and Palestine; 5 Middle Arabian Countries, namely Egypt, Iraq, Sudan, Somalia and Djibouti; and one East Country, namely Comoros. The population of the 22 countries is around 369 millions, as per 2011 data. The population growth is quite high as compared with 15 and 27 European Council 
Countries. The population of 15 EU countries, consisting of Austria, Belgium, Denmark, Finland, France, Germany, Greece, Ireland, Italy, Luxembourg, Netherlands, Portugal, Spain, Sweden and United Kingdom, is 355 millions considering 2011 data. This is very close to the population of the 22 Arab World countries. The 27 EU countries consist of the earlier 15 ones beside Bulgaria, Cyprus, Czech Republic, Estonia, Hungary, Latvia, Lithuania, Malta, Poland, Romania, Slovak Republic and Slovenia. The total population of the 27 countries is around 499 millions.

The importance of this study lies in the limited traffic safety-related literature and scarce historical data related to the Arab Countries; especially when compared with the developed ones.

\section{OBJECTIVES AND STUDY APPROACH}

This study aims to analyse and model vehicular development, traffic deaths and death rates during the past three decades in the Arab countries and compare the current and future trends with EU countries.

The data simply consist of population, which is the easy part, vehicle fleet and traffic death records, which are the difficult and problematic part in the Arab countries. In fact, the study covers the 22 Arab countries along with the earlier mentioned 15 and 27 EU countries. The data for each country are gathered from official reports and web sites, well-known international databases, research literature and direct contacts. The data for the Arab countries required special attention since the published data, other than population details, are scarce. Therefore, some are obtained through official contacts with the researchers and various Traffic Directorates. The historical vehicle fleets, death frequencies and death rates in the Arab countries along with their future predictions are compared with those for 15 and 27 EU countries using scattered diagrams and regression models. The death rates considered here are per population and per registered vehicles. The rates per vehicle-miles are not considered here due to lack of necessary data in most of the Arab world for the past 30 years. This is also true for data for other vulnerable users. Future predictions are based on best least-squares regression fit. Sophisticated modelling techniques such as multivariate analysis and artificial intelligence such as neural network and fuzzy system [1], are yet not necessary for such a quantitative or deterministic singular predictor data with years. The simplest form of many of these techniques minimizes the error square as in least-squares error method. In fact, the artificial intelligence techniques have received much attention in the area of traffic forecasting because of the ability to approximate any degree of complexity and work without prior knowledge of problem solving [2]; which is not the case here. The models tested here include, among many others, linear, exponential, quadratic, cubical, polynomial, power, inverse, compound, S-curve, growth and logarithmic. The data from different sources are cross checked, since the data for 1980s, from past official literature, do not always match those published more recently. Ambiguous and contradicting ones, as in the case of sudden change in successive years, are double checked from more than one source. Least rationale and logical ones are excluded.

\section{DATA}

The majority of the data are gathered from official publications and web sources, as for Bahrain, Qatar, Saudi Arabia, Kuwait, Oman, UAE, Algeria, Yemen, Morocco and Tunisia, and from several well-known data bases like International Road Federation, as IRF World Road Statistics [3], EU Road Federation, as European Road Statistics [4], Economic Commission for Europe, as Statistics of Road Traffic Accidents in Europe [5], International Traffic Safety Data and Analysis, as IRTAD Group [6], World Health Organization, as the International Status Report on Road Safety Call for Action [7,8] and UK Department of Transport, as Transport Statistics for Great Britain [9]. Several Annual fact books were also used to gather thedata published through official bodies, as General 
Directorate of Traffic in Bahrain [10], Oman [11] and Dubai [12], Public Security in Saudi Arabia [13] and Ministries of Planning. Europe data are well established and are widely available in several European data bases. The casualty and vehicle data for most of the Gulf Cooperation Council (GCC) countries are gathered through official contacts involving Bahrain Directorate of Traffic with various corresponding directorates. It took over 8 months to compile the necessary data for 18 Arab countries, out of the 22, together. The data for Somalia, Djibouti, Comoros and Mauritania are not available except rough estimates for few recent years. However, the influence of the data from these countries on the overall analysis is minimal since the vehicle and death data from these countries, based on the most recent available data, account for only $2.4 \%$ and $1.8 \%$, respectively, of the total 22 Arab countries. As a result, the overall data are adjusted to account for the missing data points as per their available recent percentages. This might not be the best assumption since the percentages of these countries 20 or 30 years back might not be as the current ones. However, due to lack of any data, this might give a just assumption.

The gathered historical crash death data for over three decades, along with vehicle fleets and death rates, are probably presented for the first time in the literature.

While missing fatality data for the 27 EU countries were less than $5 \%$ for the considered period (1978-2011), mostly being from the Eastern European countries; those in the 18 Arab countries were around $20 \%$. The missing vehicular data were as much as $26 \%$. However, around 1520 data points were processed for each of the 45 considered countries; which totals to around two-third of a million data points for the all the considered countries. Many data points are yet to be completed. Any missing vehicle or population data points are replaced with either an interpolated value in case it falls between two known values; or a predicted one if otherwise. The latter are based on average growth rates for the closest 8-10 years data points. The data for Czech and Slovak Republics prior to 1992 are jointly considered since no records are found for each country individually during the former Czechoslovakia time. The data for Saudi Arabia are based on Arabic calendar year, which is about $3.2 \%$ lesser than the Gregorian calendar.

It is worth mentioning that underreporting of the official registered records is not considered here, since such data are not available for almost all the Arab countries except for the last couple of years for very few Arab countries. Though several official records are fairly accurate, as in Bahrain, Qatar, Kuwait, Oman, Jordan, Tunisia and UAE; others are not as accurate as should be like in Sudan, Egypt, Algeria and Libya [14].

\section{MAIN RESULTS}

\subsection{Vehicular development}

The vehicle population in the 22 Arab countries, after being adjusted for the missing countries, has increased from just around 8 millions in 1980 to 48 millions in 2011 (Table 1). It has multiplied six times in 32 years time. That in 15 and $27 \mathrm{EU}$ countries increased by $70 \%$ and 85\%, respectively; since 1980, which is less than double. The current vehicle population in the Arab countries represents only $5 \%$ of the worldwide vehicle population. That in 27 EU countries represents over $30 \%$ of the worldwide count. The vehicular development since 1980 is regressed against the years using the earlier mentioned techniques. The models best fitted the data for Arab and EU countries are presented in Table 2. The predicted vehicle fleet for a decade time, based on the regressed models with high $R^{2}$ values of at least 0.98 , shows significant increase in the vehicle fleets. The vehicle population in the Arab countries will approach 73 million by the year 2022 (Table 2, exponential model). That in the $27 \mathrm{EU}$ countries is 356 million vehicles based on an S-curve model. This is $23 \%$ greater 
Table 1: Registered vehicle fleet in the Arab and EU countries (in millions).

\begin{tabular}{cccccccc}
\hline Year & $\begin{array}{c}22 \mathrm{Arab} \\
\text { countries }\end{array}$ & $\begin{array}{c}15 \mathrm{EU} \\
\text { countries }\end{array}$ & $\begin{array}{c}27 \mathrm{EU} \\
\text { countries }\end{array}$ & Year & $\begin{array}{c}\text { 22 Arab } \\
\text { countries }\end{array}$ & $\begin{array}{c}15 \mathrm{EU} \\
\text { countries }\end{array}$ & $\begin{array}{c}27 \mathrm{EU} \\
\text { countries }\end{array}$ \\
\hline 1980 & 8.25 & 135.95 & 149.25 & 1998 & 21.88 & 193.92 & 221.25 \\
1982 & 10.44 & 144.11 & 158.91 & 2000 & 24.85 & 202.91 & 232.74 \\
1984 & 12.53 & 152.27 & 168.60 & 2002 & 26.45 & 215.13 & 247.56 \\
1986 & 14.00 & 159.99 & 177.35 & 2004 & 28.99 & 219.27 & 254.35 \\
1988 & 15.22 & 164.87 & 183.51 & 2006 & 32.69 & 221.70 & 258.36 \\
1990 & 16.73 & 167.73 & 188.79 & 2008 & 36.90 & 226.85 & 269.07 \\
1992 & 18.36 & 168.00 & 193.21 & 2010 & 44.65 & 231.17 & 275.43 \\
1994 & 19.61 & 175.80 & 197.87 & 2011 & 47.83 & NA & NA \\
1996 & 20.45 & 183.48 & 208.29 & & & & \\
\hline
\end{tabular}

Table 2: Best-fit models for vehicle fleet prediction in Arab and EU countries (data 1978 to 2011 for Arab countries and 1980 to 2010 for EU ones).

\begin{tabular}{lcccccc}
\hline Countries & $\begin{array}{c}\text { Vehicles } \\
(2010 \text { data) }\end{array}$ & Type & Model & $R^{2}$ & $F$ & $\begin{array}{c}\text { Prediction } \\
\text { for } 2022\end{array}$ \\
\hline Arab & $44,651,001$ & Linear & $1,047,775.5482 \mathrm{x}-$ & 0.919 & 341 & $50,063,581$ \\
& & & $2,068,188,762$ \\
& & Compound & $6.91008 \mathrm{e}-38 * 1.052641^{\mathrm{x}}$ & 0.967 & 636 & $77,717,305$ \\
& & Exponential & $9.6076-\mathrm{E} 35^{*}$ & 0.980 & 1507 & $72,708,480$ \\
$27 \mathrm{EU}$ & \multirow{2}{*}{$275,426,578$} & Linear & $4234370.2484^{*} \mathrm{x}-$ & 0.984 & 1765 & $325,657,968$ \\
& & & 8236238674 \\
& & S curve & $\exp (59.48355-80458.89 / \mathrm{x})$ & 0.987 & 2287 & $356,489,198$ \\
& & Growth & $\exp (-21.17784756951474$ & 0.987 & 2272 & $358,806,168$ \\
& & & $+0.020216 * \mathrm{x})$ & & & \\
\hline
\end{tabular}

than the 2011 vehicle population. This means that around 28 million extra vehicles in the Arab countries will be added to the current 45 million's record, as per 2010 records. That in 27 EU countries is 81 million vehicles. This means that an extra 109 million vehicles will be pumped into the global road network by the year 2022 from just these two regions. This is almost $13 \%$ of the current global 850 million vehicles from just Arab and EU Countries.

In fact, the annual growth rate of the vehicle development during the past 15 years reflects a much higher estimate than that predicted from the models. This is because the trend in the vehicle development during the past 15 years looks steeper than that for the period between 1978 and 1995 (Table 1). The other way round is true for the EU countries; in which the recent trend looks flatter. This is quite logical since the EU countries have developed their sustainable mass transit system long back. That in many Arab countries are still to be developed. As a result, the rider share of the public modes in the EU countries is far greater than that in the Arab countries. To consider such fluctuations and to reduce the cumulative effect of the error square of the earlier models, the data are regressed once again for 


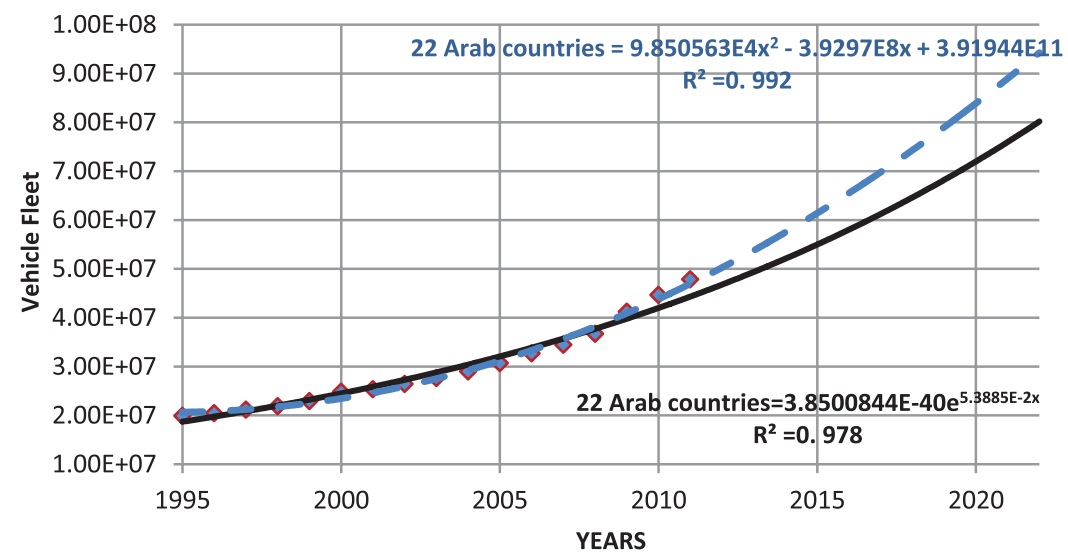

Figure 1: Vehicle development and best-fitted models for the total 22 Arab countries (1995-2011).

the period from 1995 to 2010/2011 so as to have a closer and more reasonable fit the data for the recent years. The best fits along with the predicted values are presented in Fig. 1. As can be seen from the figure, the data for the Arab countries are bound between an upper limit through a quadratic model and a lower one through a power model. The latter shows an estimate of 80 million vehicles for the year 2022 and the former shows 97 millions. Both are greater than the earlier estimates. These indicate, on average, an increase of around 100\% compared with 2010 record. This means an extra 44 million vehicles by the year 2022. Similarly, the data for the $27 \mathrm{EU}$ countries are bound between a lower limit, considering a linear fit, and a higher one considering an exponential fit. The prediction for the year 2022, on average, shows an increase of $16 \%$ since 2010; which is around 73 million extra vehicles. The increase by the year 2022 from the two regions approaches 117 million vehicles. This is around $15 \%$ of the current global vehicle population.

While such an increase looks very encouraging for vehicles' manufacturers; its environmental consequences are not. According to the EU commissions, the renewed sustainable transport in Europe must meet economic, social and environmental conditions [15]. Currently, none are applied in most of the Arab countries. However, such conditions, placed by EU commissions, will force manufacturers to innovate a more sustainable personal mobility.

It is worth mentioning that the average annual growth rate in the vehicle fleet during the past three decades in the Arab countries is $7.8 \%$ compared with $1.2 \%$ in 27 EU countries. There is, yet, no clear plan to encourage travellers to shift towards safer and more sustainable mode of transport in most of the Arab countries, though congestion in major cities is a serious problem. In exception to many Arab cities; Dubai and Cairo have succeeded to provide an efficient Mass Transit System (MTS) to their busy networks. MTS is necessary to control users exposure to accidents by shifting some of the car users towards other safer modes of transport. Murray Mackay [16] considers the latter among the important pillars of any Traffic Safety Strategies.

\subsection{Fatality trends}

The total crash deaths in the 22 Arab countries, after being adjusted for the missing countries' data, increased from 22,328 victims during 1980 to 37,952 during 2011 (Fig. 2). Such drastic increase in death records is in total contradiction with the direction of the death trends in the EU countries. The crash deaths in 15 and 27 EU countries dropped from 59,879 and 74,876, in respective order, during 


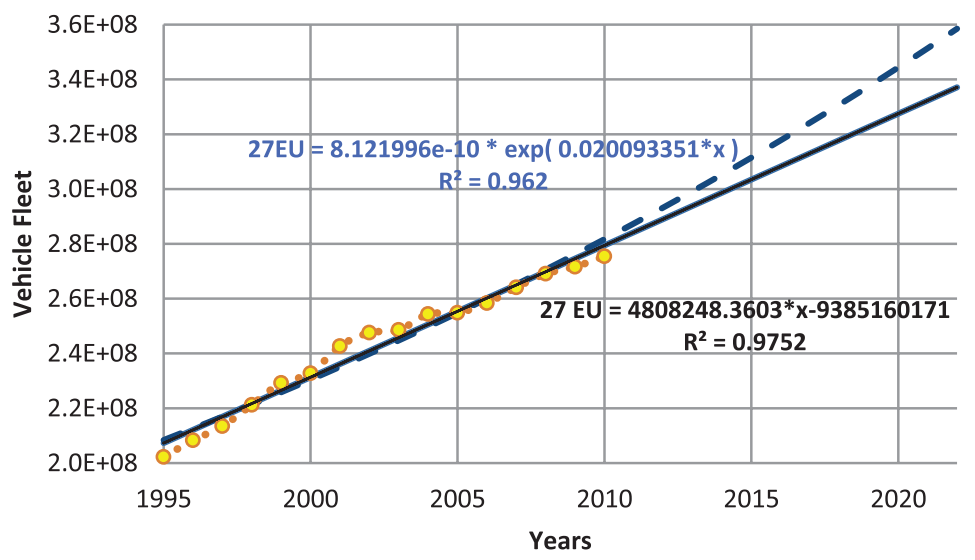

Figure 2: Vehicle development and best-fitted models for the total 27 EU countries (1995-2011).

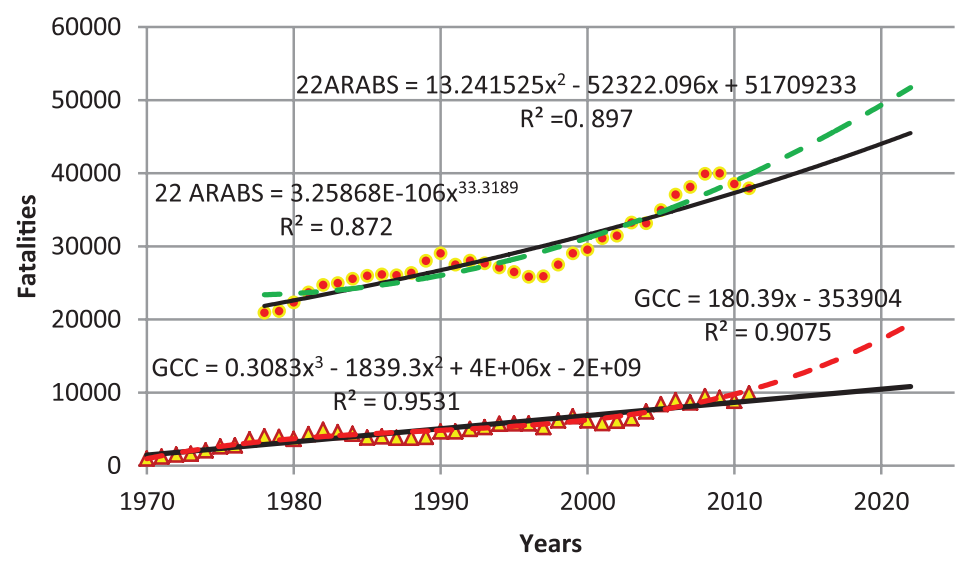

Figure 3: Fatality trends in GCC and Arab countries and their corresponding best fits since 1970/1978.

1980 to 20,764 and 30,170, respectively, during 2011 (Fig. 3). While these are about one-third and two-fifth of the 1980 records in 15 and 27 EU countries, respectively; that in the Arab world is just under twice that of the 1980 records. Such high increasing trend in the Arab countries raises serious questions regarding the counteract safety plans and the effectiveness of the official efforts towards such serious public health problem.

According to various tested regression models, such an increasing trend in the Arab world will continue during the coming decade. The predicted traffic death in the Arab countries for the year 2022, considering data since 1978 (Fig. 3), is expected to be within an envelope of 46-52 thousand deaths. That in 27 EU countries, as per cubical and exponential regression models shown in Fig. 4, drops to a lower bound of 26 thousand deaths and an upper bound of 32 thousand deaths by the same year. In fact, this is even lesser than that for the six GCC countries, which represent only $11 \%$ of the total Arab population, though the population and vehicle fleet in the GCC countries are as little as 


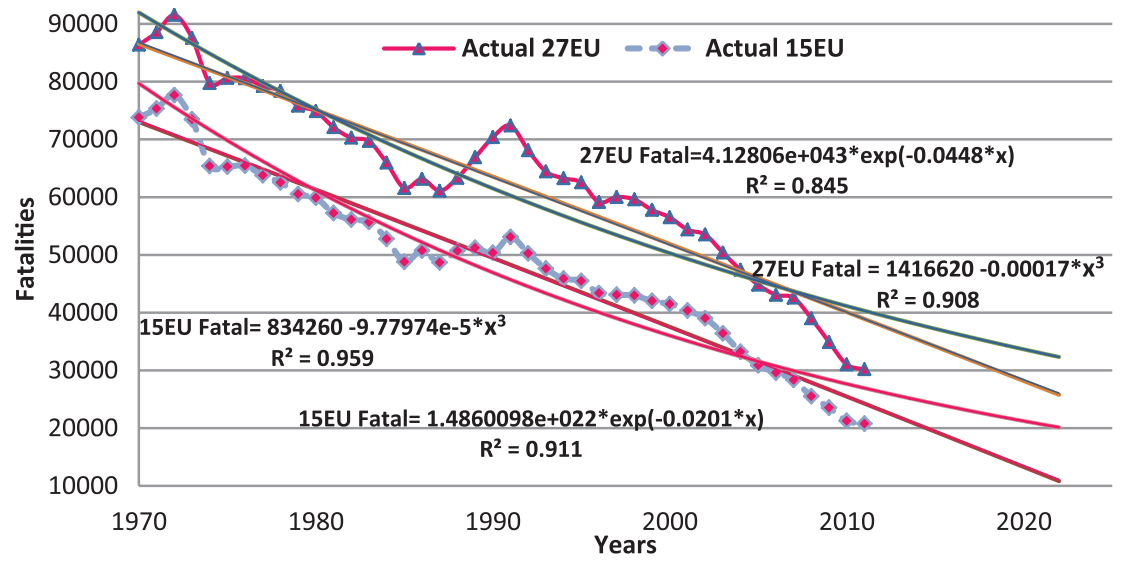

Figure 4: Traffic death trends in 15 and 27 EU countries and their corresponding best fits since 1970.

$8 \%$ and $5 \%$, respectively, of that in the 27 EU countries. The predicted traffic death in 15 EU countries is between 11 and 20 thousands deaths by the year 2022 .

According to various tested regression models, such an increasing trend in the Arab world will continue during the coming decade. The predicted traffic death in the Arab countries for the year 2022, considering data since 1978 (Fig. 3), is expected to be within an envelope of 46-52 thousand deaths. That in 27 EU countries, as per cubical and exponential regression models shown in Fig. 4, drops to a lower bound of 26 thousand deaths and an upper bound of 32 thousand deaths by the same year. In fact, this is even lesser than that for the six GCC countries, which represent only $11 \%$ of the total Arab population, though the population and vehicle fleet in the GCC countries are as little as $8 \%$ and $5 \%$, respectively, of that in the 27 EU countries. The predicted traffic death in 15 EU countries is between 11 and 20 thousands deaths by the year 2022 .

The earlier crash deaths for the year 2022 in the Arab countries are in excess of just about $20 \%$ of the 2011. This is quite unrealistic; since the annual growth rate in the death records and their general trends during the past 15 years reflect a much higher estimate. In fact, the death record is expected to reach four times the earlier estimate as per average annual growth rate in roadway deaths; considering the past 15 years' data. The other way round was true for the EU countries. To adjust such estimates and to reduce the cumulative error square effect of the earlier models; the death records are regressed once again using the data for the period from 1995 to 2011. This will lead to a closer and more reasonable fit to the data for the recent years. As a result, the best fits along with their corresponding predicted values are presented in Table 3. The upper and lower limits for the year 2022 based on linear and power models are within 51-57 thousand deaths. These are substantially higher than the earlier estimates. The previous range for the year 2022, on average, represents around 45\% increase since 2011 . All the other tested models followed very similar trends of the earlier two models.

The crash death prediction for 27 EU countries is within 9400, as per cubical fit, and 20,300 deaths, as per exponential fit. Logarithmic and inverse fits showed similar estimates to the former cubical model, with slightly lower $R^{2}$ values. Power, growth and S-curve fits presented similar fits to the latter exponential model. The earlier range, on average, represents less than half the current record. The expected range for the predicted traffic deaths for the year 2022 for the 15 EU is 3-13 thousands deaths (Table 3). 
Table 3: Best-fitted models for traffic deaths for Arab and EU countries (based on data for the period from 1995 to 2011).

\begin{tabular}{|c|c|c|c|c|c|}
\hline Countries & $\begin{array}{c}\text { Current } \\
\text { deaths } \\
\text { (year 2011) }\end{array}$ & Developed models & $R^{2}$ & $F$-test & $\begin{array}{l}\text { Predicted } \\
\text { deaths (year } \\
\text { 2022) }\end{array}$ \\
\hline \multirow[t]{2}{*}{ Arab } & \multirow[t]{2}{*}{37,952} & $968.8352 * x-1907640$ & 0.943 & 249 & 51,345 \\
\hline & & $8.1166684 \mathrm{E}-194 \mathrm{x}^{59.849}$ & 0.945 & 259 & 57,316 \\
\hline \multirow[t]{2}{*}{ GCC } & \multirow[t]{2}{*}{9901} & $288.5777 x-570646$ & 0.859 & 92 & 12,857 \\
\hline & & $10.431351 x^{2}-41499.416 x+41279778$ & 0.881 & 92 & 16,370 \\
\hline \multirow[t]{2}{*}{$15 \mathrm{EU}$} & \multirow[t]{2}{*}{20,764} & $7.186001 \mathrm{e}+48 * \exp (-0.05096 * \mathrm{x})$ & 0.931 & 217 & 12,709 \\
\hline & & $1135402-0.000136988 * x^{3}$ & 0.964 & 398 & 2937 \\
\hline \multirow[t]{2}{*}{$27 \mathrm{EU}$} & \multirow[t]{2}{*}{30,170} & $4.1280655 \mathrm{e}+43 * \exp (-0.04476 * x)$ & 0.928 & 194 & 20,272 \\
\hline & & $1416620-0.000170 * x^{3}$ & 0.963 & 394 & 9357 \\
\hline
\end{tabular}

Once again, such trends in the Arab countries show serious traffic safety concerns, since the fatality trends in the developing countries show continuous dropping patterns and will continue dropping during the coming decade; and the trends in the Arab countries show continuous increasing patterns and will continue doing so during the coming seen future.

Though many factors lead to the earlier high number of crash deaths in the Arab World and require careful attention, urban planning of the infrastructure in most of the Arab countries is not a forgiving one. They do not support Traffic Safety Plans; especially that related to exposure control towards accidents. Another sector requiring intensive improvement is human behaviour development, since generally over half of crash fatalities in many Arab countries are related to speed, red light crossing and not obeying the rules. It is quite important to mention that while the western drivers comprehend over $74 \%$ of the posted signs; GCC drivers understand only $51.8 \%$ of them $[17,18]$. The comprehension of other Arab drivers of posted signs is 56.4\% [19].

\subsection{Fatality rates}

The average crash fatality rates per 100,000 population in the Arab countries showed a fairly decreasing pattern during the years from 1980 to 1996 (Fig. 5). In fact, the rates showed to be far lesser than that in EU countries. However, this should not wrongly be interpreted that these countries were doing quite well or better than EU in traffic safety. The rates in the Arab countries are quite misleading because of the clear difference in the vehicle ownership rate and average vehicle-miles travelled. While the former in the EU countries is one vehicle per 1.8 population, that in the Arab countries is one per 7.4 population. The vehicle-miles travelled in the Arab countries though are not yet easy to be estimated, it is surely lesser than that in the EU countries. As the vehicle ownership is expected to increase, as discussed earlier, along with the vehicle-miles travelled; the crash deaths are also expected to escalate if no clear traffic safety plans are imposed. The fatality rates showed an increasing trend afterword. The overall fatality rates for the 15 and $27 \mathrm{EU}$ countries were in the range of 14-17 deaths per 100,000 population during early 1980s; as been said which were clearly higher than that of the Arab countries. The rates in the EU countries decreased continuously during the past three decades. The rates will continue doing so during the coming decade according to the models developed here and are shown in Fig. 4. That in the Arab world is not as clear as in EU countries, since the rates in the Arab countries showed a clear dropping trend until 1997, then started escalating 
Table 4: Developed models for fatalities per 100,000 population based on data 1995 to 2011.

\begin{tabular}{lccrrr}
\hline & $\begin{array}{c}\text { Fatality } \\
/ 100,000 \text { pop } \\
\text { (year 2011) }\end{array}$ & Developed models & $R^{2}$ & $F$-test & $\begin{array}{c}\text { Predicted } \\
\text { rate (year } \\
2022)\end{array}$ \\
\hline Arab & 10.23 & $165-309326 * \mathrm{x}^{-1}$ & 0.496 & 5 & 11.88 \\
$15 \mathrm{EU}$ & 5.24 & $323-3.902781848436275 \mathrm{E}-8 * \mathrm{x}^{3}$ & 0.970 & 86 & 0.07 \\
$27 \mathrm{EU}$ & 6.04 & $-0.45042 * \mathrm{x}+912$ & 0.970 & 78 & 1.46 \\
\hline
\end{tabular}

till 2009. The rates dropped slightly afterward. Nevertheless, they are expected to continue dropping gently during the coming decade. Currently, the overall rates for the EU countries is in the range of 5-6 deaths per 100,000 inhabitants, which is half that of the average Arab countries. However, the gap between them is also expected to continuously increase with the time, as per developed models, if no proper counter action is considered.

The fatality rates in EU and Arab countries for the period after 1995 follow slightly different trend than that prior to 1995. To improve the models presented in Fig. 4, as done for the fatalities; the data since 1995 are regressed once again. The models are shown in Table 4.

While cubical model, with very high $R^{2}$ value of 0.97 , shows that fatality rates per 100,000 population in $15 \mathrm{EU}$ countries will asymptotically tend to approach zero in just over a decade time; an inverse model for the Arab countries, with $R^{2}$ value of 0.50 , shows that the annual death rate will be close to 12 deaths per 100,000 population. That for the $27 \mathrm{EU}$ countries will be close to 1.5 . In other words, while the death rates per population in the various EU countries drop drastically towards zero, or at least will be heading towards it, by the year 2022; the rate in the Arab countries will increase by $16 \%$ considering the data since 1995 .

The traffic crash death rate per 10,000 vehicles in 15 and 27 EU countries, once again, will asymptotically tend to close to zero, or at least it will be heading towards it, in about a decade time (Fig. 5) as per linear, logarithmic, inverse and cubical models with $R^{2}$ greater than 0.955 . The trend is expected to go closer and closer to zero with time; but will not reach the absolute zero in the foreseeing future with the current transport facilities. Such trends remind us with the effectiveness of Swedish 'Vision Zero' strategies [21]. Honestly, most of the researchers during early 1990s thought that such plans were unachievable. The historical data showed that such a vision is not an imaginary one. However, the earlier finding is further confirmed, with $R^{2}$ of greater than 0.995 , when the models are further refined for the data since 1995. However, exponential and compound models showed an upper limit of death rates per 10,000 vehicles of 0.46 and 0.60 in a decade time for 15 and 27 EU countries, respectively (Table 5). These are about half the rates of the year 2011.

Contrary to the EU countries, the trends in the Arab countries do not follow such clear descending trends. Nevertheless, unlike the death rate trend per 100,000 population in the Arab countries; the trend of death per 10,000 vehicles in the Arab countries showed a clear decreasing pattern from an average 27 deaths per 10,000 vehicles during 1980 to 8 in 2011. The latter in the 27 EU countries dropped from 5.02 to 1.13 , respectively (Fig. 5). According to a regressed exponential model, which best fitted the data with $R^{2}$ value of 0.94 , the rate is expected to further drop during the coming decade (Fig. 6). It is quite important to mention that the death rates during the period from 1996 to 2008 were in the range of 11-12.5. The death rate per 10,000 vehicle for the year 2022 using the past 15 years data is expected to drop slightly by the year 2022 . According to best regressed model shown in Table 5, the death rate will drop to 6.8 by the year 2022. This is around $10 \%$ lesser than the current 
Table 5: Developed models for fatalities per 10,000 vehicles based on data since 1995.

\begin{tabular}{|c|c|c|c|c|c|}
\hline Countries & $\begin{array}{c}\text { Fatality/10,000 } \\
\text { vehicles (year } \\
\text { 2010\2011) }\end{array}$ & Developed models & $R^{2}$ & $F$-test & $\begin{array}{c}\text { Predicted rate } \\
\text { (year 2022) }\end{array}$ \\
\hline Arab & 7.90 & $-468+960413.952 * \mathrm{x}^{-1}$ & 0.778 & 73 & 6.82 \\
\hline $15 \mathrm{EU}$ & 0.92 & $3.406458158 \mathrm{E}+57 * 0.9362 \mathrm{x}$ & 0.978 & 35 & 0.46 \\
\hline $27 \mathrm{EU}$ & 1.13 & $4.05083889 \mathrm{E}+54 * 0.9395 \mathrm{x}$ & 0.978 & 34 & 0.60 \\
\hline
\end{tabular}

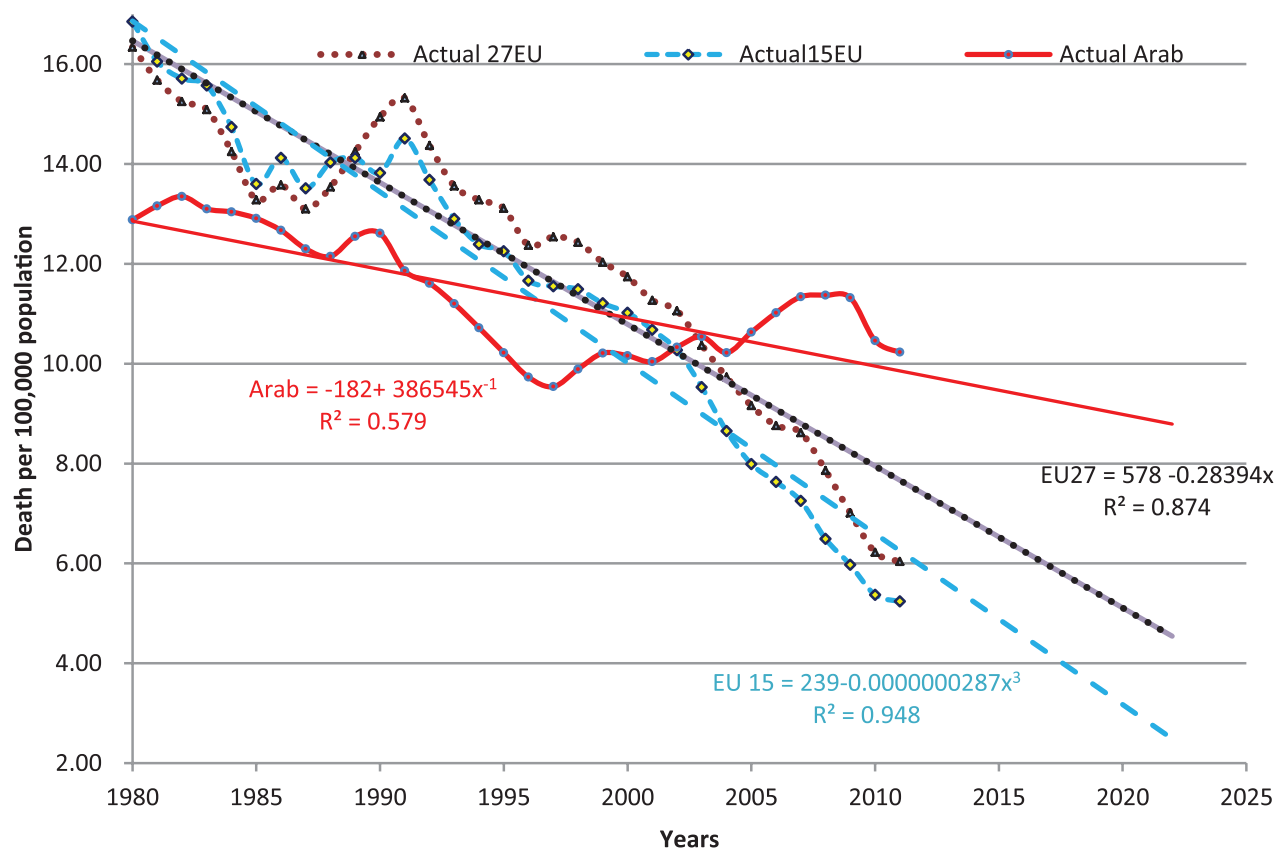

Figure 5: Trend in the traffic deaths rates in the Arab, 15 EU and 27 EU countries (1980-2011).

7.9 rate. The current death rate per vehicles is at least 7 times that of the EU countries. That predicted for the year 2022 is over 11 times EU rates.

Once again, such poor safety records in the Arab World require careful reading, proper interpretation of the results and extensive research since many contributing factors lead to such high rates of traffic deaths. These include, among many others, lack of measurable long-term traffic safety plans, inconsistent handling of traffic safety strategies, poor involvement of Non-Governmental Organization (NGO) in traffic safety problem, poor coordination between various stake holders, poor research involvement in the traffic safety crises and limited post-accident rehabilitation centres. However, the earlier weaknesses do not mean exclusion of successful programs. For example, Riyadh, capital of Saudi Arabia, Dubai, in UAE, Bahrain, and several other cities have involved lots of efforts, especially in human behaviour and enforcements, to reduce traffic fatalities.

Many EU countries sat long-term national safety plans since the 1970s and 1980s for the traffic casualty reduction. In 1987, a target was set in UK, for example, to reduce road casualties by one-third 


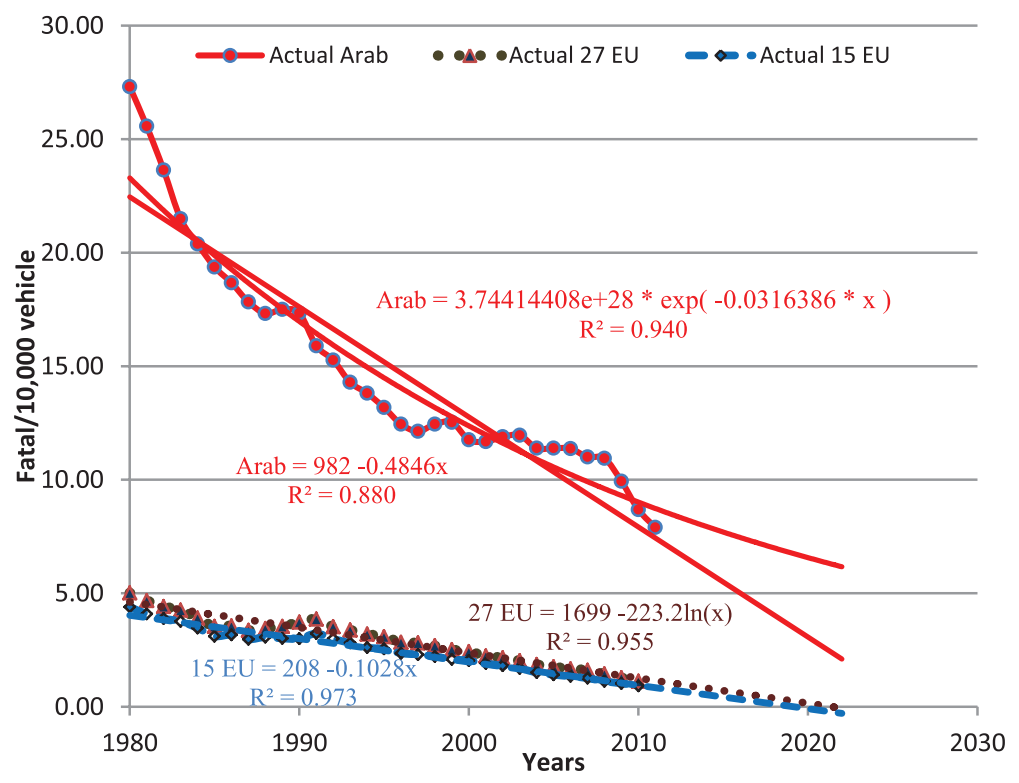

Figure 6: Fitted models for Arab and EU countries using data since 1980.

by the year 2000 [20]. As a result, road death has fallen by $39 \%$ and serious injuries by $45 \%$. The target was successfully met. In 2000, the officials sat a plan to further reduce crash deaths and severe injuries by $40 \%$ by the year 2010. They have fairly succeeded in approaching the sat target [21]. There are many other similar successful stories throughout the 15 EU countries to improve the current plans and follow them up. The Swedish National Road Administration employed their 'Vision Zero - From Conceptual to Action' plan [21]. The Danish Road Safety Commission employed 'Every Accident is One Too Many' targeting 40\% deaths reduction [22].

There are great opportunities to transfer such experience to the Arab countries through the various involved bodies such as consulting offices, research institutions and contractors. Some, as TRL and Sewe-Road, are already involved in developing traffic safety plans and procedures for casualty reductions in the region. Manufacturers may also involve better vehicle high-tech to suite the regional problems since over 32 million extra vehicles are expected to be added to the current 48 million vehicles by the year 2022. Supporting traffic safety through ITS and administering the traffic more efficiently are also sectors requiring further investigation in the region.

\section{CONCLUSIONS AND RECOMMENDATIONS}

Over three decades, roadway vehicular data, death records and death rates per population and per vehicles are presented for the Arab countries. The rate per vehicle-miles was not possible to be considered here due to lack of necessary historical data concerning average annual mileage in the Arab countries. Such data are thought to be presented for the first time in the literature. The data are analysed, modelled and compared with 15 and 27 EU countries. In total, around two thirds of a million data points are processed for the considered $45 \mathrm{Arab}$ and EU countries. The vehicular predictions for the year 2022 show an increase of $100 \%$ in the Arab countries and 16\% in the EU ones compared with 2010/2011. These mean extra 44 million and 73 million vehicles, in respective order. The sum of the two accounts for around $16 \%$ of the current global vehicle population. While such an increase 
looks very encouraging for vehicle manufacturers, its environmental consequences and power conservation are not.

Traffic crash records in 22 Arab countries summed up to 22,320 fatalities during 1980. Those in 15 and 27 EU countries were 59,879 and 74,876 deaths, respectively. Since then, the death records in the Arab countries escalated by over $70 \%$ to reach 37,952 during 2011. Contrary to this, traffic death in EU countries showed a substantial drop with the time. The crash deaths records in 15 and 27 EU countries showed 20,764 and 30,170 deaths in 2011, respectively. These are about one-third and two-fifth, in respective order, of the 1980 records. The fatality trend in the Arab countries during the past three decades was far above the international norms.

The upper and lower death limits for the year 2022 based on linear and compound models are within 51-57 thousand deaths. The average represents an increase of around $45 \%$ since 2011 . The predicted limit for $27 \mathrm{EU}$ countries is within 9400 deaths, as per cubical fit, and 20,300, as per exponential fit. The average represents less than half of the current record. The expected range for the 15 EU countries is 3-13 thousands deaths. On average, the latter represents $<39 \%$ of the current record.

The crash death rates showed a continuous descending trend in the EU countries during the past three decades and will continue doing so during the coming decade. That in the Arab world will also continue dropping gently during the coming decade. The gap between Arab and EU countries is continuously increasing with time and is expected to do so during the coming decade unless proper counteractions are considered. Furthermore, the rates in the Arab countries are quite misleading because of the clear difference in the vehicle ownership rate and average vehicle-miles travelled between the Arab countries and EU ones. The fatality rates per 100,000 population and per 10,000 vehicles in $15 \mathrm{EU}$ countries will asymptotically head towards zero in about a decade time. That in the Arab countries is not so. An inverse model shows that the annual death rate will be close to 12 deaths per 100,000 population in a decade time. That for the $27 \mathrm{EU}$ countries will be close to 1.5. In other words, while deaths rates per population in EU countries drop drastically by the year 2022, the rate in the Arab countries will increase by $16 \%$. The rate per 10,000 vehicles will drop by $10 \%$.

Such poor safety records in the Arab countries require careful reading, proper interpretation of the results and extensive research since there are many factors leading to such high rates in traffic deaths.

\section{REFERENCES}

[1] Gazder, U., Application of neural network for mode choice modelling and modal traffic forecasting, Ph.D. Thesis, Department of Civil and Environmental Engineering, King Fahd University of Petroleum and Minerals, Dhahran, Saudi Arabia, 2014.

[2] Ortuzar, J.D. and Willumser, L.G., Modelling Transport, 3rd edn, John Willey: New York, 2002.

[3] International Road Federation, IRF World Road Statistics, Geneva Programme Centre: Switzerland, Series 2004 to 2010.

[4] European Union Road Federation, European Road Statistics 2008, The Voice of the European Road, Series from 2008 to 2010. doi: http://dx.doi.org/10.4324/9781315876481

[5] Economic Commission for Europe, Statistics of Road Traffic Accidents in Europe 1994, UN: Geneva, Series 1991, 1994, 1995.

[6] Organization for Economic Co-Operation and Development. International Traffic Safety Data and Analysis Group, available at www.cemt.org/irtad/IRTADPUBLIC/weng1.html, 2008 (accessed November 2010).

[7] World Health Organization, International Status Report on Road Safety Call for Action, Regional Office for the Eastern Mediterranean, available at www.who.int/violence_injury_ prevention/road_safety_status_2009, 2010. 
[8] World Health Organization, Eastern Mediterranean Status Report on Road Safety Call for Action, Regional Office for the Eastern Mediterranean, 2010.

[9] The Department of Transport, Transport Statistics: Great Britain Casualty Report", A Publication of the Government Statistics Service, HMSO: London, UK, Series 1992 to 2007.

[10] General Directorate of Traffic, Traffic Accident Facts in Kingdom of Bahrain, Ministry of Interior, Bahrain Series 1970 to 2011.

[11] Directorate General of Traffic, Facts and Figures 2012, Royal Oman Police: Oman, 2012.

[12] General Traffic Department, Traffic Accident Facts in Dubai, Ministry of Interior: Dubai, UAE, Available at: www.dubaipolice.gov.ae/portal/downloads/ACCIDENTFACTS2003.pdf, 2003.

[13] General Directorate of Traffic, Annual Statistical Report, Department of Traffic Studies, Public Security, Ministry of Interior: Riyadh, Saudi Arabia, 2006.

[14] Al-Madani, H.M.N., Fatal crashes in GCC countries: comparative analysis with EU countries for three decades, WIT Transactions on the Environment, 134, pp. 471-482, 2013, ISSN 17433509, doi:10,2495/SAFE 130421.

[15] Murray, R.B., Murphy, M. \& Ahern, A., Issues associated with planning, implementing, managing and operating public transport projects in Ireland. Proceedings XIX Urban Transport and Environment, ed. C. A, Brebbia, WIT press: UK, 2013. doi: http://dx.doi.org/10.2495/ $\underline{\mathrm{ut} 130071}$

[16] Mackay, M., Reducing traffic injury: a global challenge, Safety on Road: An International Conference (SORIC' 98), University of Bahrain: Bahrain, pp. 397-400, 1998.

[17] Al-Madani, H.M.N. \& Al-Janahi, A.R., Role of drivers' personal characteristics in understanding traffic sign symbols. Accident Analysis and Prevention, 34, pp. 185-196, 2001. doi: http:// dx.doi.org/10.1016/s0001-4575(01)00012-4

[18] Al-Madani, H.M.N. \& Al-Janahi, A.R., Assessment of drivers' comprehension of traffic signs based on their traffic, personal and social characteristics. Transportation Research: F, Traffic Psychology \& Behaviour, 5, pp. 361-374, 2002. doi: http://dx.doi.org/10.1016/s1369$\underline{\text { 8478(02)00006-2 }}$

[19] Al-Madani, H., Prediction of drivers' recognition of posted signs in five Arab countries. Perceptual and Motor Skills, 92, pp. 72-82, 2001. doi: http://dx.doi.org/10.2466/ pms.2001.92.1.72

[20] Department of the Environment, Transport and the Regions, Tomorrow's Roads: Safer for Everyone, The Government's Road Safety Strategy and Casualty Reduction Targets for 2010, Department of the Environment, Transport and the Regions: Wetherby: UK, 2000.

[21] Swedish National Road Administration, Vision Zero from Conceptual to Action, Swedish National Road Administration: Vagverket, Borlange, Sweden, 1997.

[22] The Danish Road Safety Committee, Every Accident is One Too Many - Road Safety Starts with You, Danish Ministry of Transport: Copenhagen, Denmark, 1998. 